\title{
IMPLEMENTASI \\ PERSETUJUAN TINDAKAN KEDOKTERAN (INFORMED CONSENT) DALAM PERJANJIAN TERAPEUTIK OLEH TENAGA KESEHATAN TERHADAP PASIEN RUMAH SAKIT DI PROVINSI BALI
}

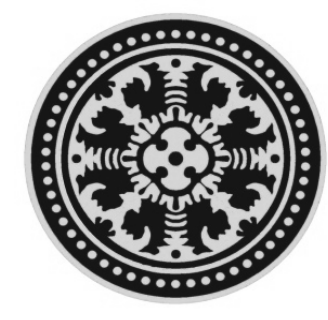

IDA AYU SRI KUSUMA WARDHANI

\author{
PROGRAM PASCA SARJANA \\ UNIVERSITAS UDAYANA \\ DENPASAR \\ 2014
}




\title{
IMPLEMENTASI \\ PERSETUJUAN TINDAKAN KEDOKTERAN (INFORMED CONSENT) \\ DALAM PERJANJIAN TERAPEUTIK \\ OLEH TENAGA KESEHATAN \\ TERHADAP PASIEN RUMAH SAKIT \\ DI PROVINSI BALI
}

Oleh :

Ida Ayu Sri Kusuma Wardhani

Mahasiswa Magister Ilmu Hukum Unud

\begin{abstract}
Health is the most important part of human life that can affect productivity and optimal human activity. When a person's health is compromised, then that person will seek treatment in health care facilities in the hospital one of them in order to get action. Measures of medicine containing the high risk should get written consent from patient/family called Informed Consent. The legal relationship between health professionals with patients occurs because of the agreement that causes the therapeutic relationship inspaningverbintenis law (treaty effort).

Similarly in the Bali Provincial Hospital in any medical act especially those containing a high risk, which is done by some health professionals are also using the Informed Consent. But if there is negligence actions that cause harm, who will be responsible for the risks in the suffering patient / family? and how the efforts of patient / family to resolve medical disputes against the risk of Informed Consent?

The method used in this research is an empirical law derived from primary data and secondary data. The nature of the study is descriptive, with qualitative data analysis. Overall the results of these analyzes are presented in the description which describes the complete problem under study, along with a critical discussion.

Based on the Theory of Legal System of L. M. Friedman, legal systems theory described by Soerjono Soekanto be legal efficacy theory, the theory of Hans Kelsen responsibility, and legislation as well as the results of research in the field, it is known that the liability of health professionals based on Informed Consent Agreement Therapeutic Hospital in Bali province is on the doctor who signed the operator of the informed consent form. However, if the patient / family prosecute acts of negligence committed by health professionals, the hospital will be responsible jointly and severally against such negligence. From the result of research in the hospital in the province of Bali, demands action against medical negligence are usually resolved by kinship means or mediation.
\end{abstract}

Keywords : Informed Consent, Liability, Law Efforts 


\section{PENDAHULUAN}

\section{Latar Belakang}

Kesehatan merupakan bagian terpenting dalam kehidupan manusia. Produktivitas dan aktivitas seseorang dipengaruhi oleh kondisi kesehatan orang tersebut. Dengan kesehatan orang dapat berpikir dengan baik dan dapat melakukan aktivitas secara optimal. Ketika kesehatan seseorang terganggu, mereka akan melakukan berbagai cara untuk dapat sehat kembali. Salah satunya adalah dengan cara berobat dan mendapatkan tindakan kedokteran di sarana-sarana pelayanan kesehatan yang tersedia seperti puskesmas, klinik, dan rumah sakit.

$$
\text { Dalam setiap tindakan }
$$
kedokteran yang mengandung resiko tinggi harus mendapat persetujuan dari pasien/keluarga pasien. Persetujuan tindakan tersebut dikenal dengan Persetujuan Tindakan Kedokteran atau dalam dunia kedokteran sering disebut sebagai (Informed Consent).

$$
\text { Informed artinya telah }
$$

diberitahukan, telah disampaikan atau telah diinformasikan. Consent artinya persetujuan yang diberikan kepada seseorang untuk berbuat sesuatu. Dengan demikian, Informed Consent adalah persetujuan yang diberikan pasien kepada dokter setelah diberi penjelasan. Pengertian demikian tidak tepat tergambar dalam Persetujuan Tindakan Medis. Namun setelah diterbitkannya Peraturan Menteri Kesehatan Nomor 585/Menkes/Per/ IX/1989, istilah Persetujuan Tindakan Medis yang resmi digunakan, kemudian dengan diterbitkannya Peraturan Menteri Kesehatan Nomor 290/Menkes/Per/ III/2008 istilah Persetujuan Tindakan Medis diganti dengan istilah Persetujuan Tindakan Kedokteran.

Pasal 1 ayat (1) Permenkes No.290/Menkes/Per/III/2008 tentang Persetujuan Tindakan Kedokteran memberikan definisi Persetujuan Tindakan Kedokteran adalah persetujuan yang diberikan oleh pasien atau keluarga terdekat setelah mendapat penjelasan secara lengkap mengenai tindakan kedokteran atau kedokteran gigi yang akan dilakukan terhadap pasien. 
Ada dua bentuk Consent luas, mencakup bidang diagnostik, (Persetujuan) yaitu : ${ }^{1}$

1. Implied Consent (tersirat atau preventif, rehabilitatif maupun promotif. $^{3}$ dianggap telah diberikan)

a. Implied Constructive Consent (Keadaan Normal/biasa)

b. Implied Emergency Consent (Keadaan Gawat Darurat)

2. Expressed Consent (dinyatakan)
a. Lisan
b. Tulisan

Hubungan dokter dan pasien dalam transaksi terapeutik (perjanjian medis). Terapeutik adalah terjemahan dari therapeutic yang berarti dalam bidang pengobatan, ini tidak sama dengan therapy atau terapi yang berarti pengobatan. ${ }^{2}$

Perjanjian terapeutik merupakan perjanjian yang terjadi antara dokter dan pasien yang bukan hanya di bidang pengobatan saja tetapi lebih

\footnotetext{
${ }^{1}$ Jusuf Hanafiah dan Amri Amir, 2008, Etika Kedokteran dan Hukum Kesehatan, Jakarta, EGC, hal 74-75.

2 Harmien Hadiati Koeswadji, 1993, Hukum Kedokteran di Dunia Internasional, Makalah Simposium, Medical Law, Jakarta, hal 142.
}

Pasal 2 Permenkes No.290/ Menkes/Per/III/2008 secara tegas menyatakan bahwa semua tindakan kedokteran yang akan dilakukan terhadap pasien harus mendapat persetujuan. Persetujuan tersebut dapat diberikan secara tertulis maupun lisan dari pasien setelah pasien mendapatkan informasi dan penjelasan tentang perlunya tindakan kedokteran dilakukan.

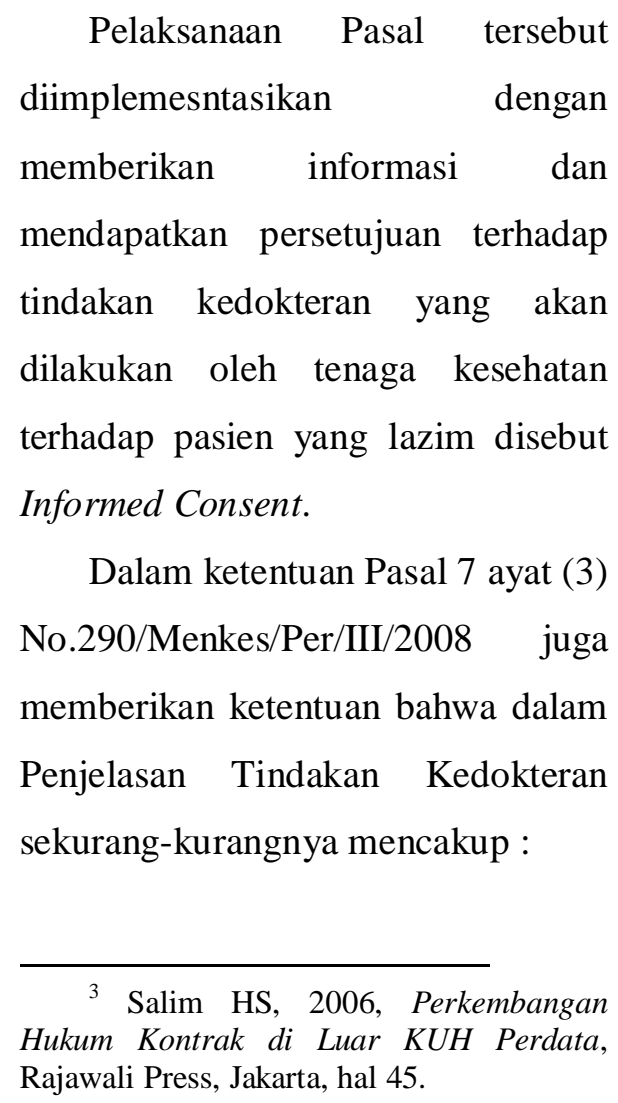


1. Diagnosis dan Tata Cara Tindakan Kedokteran;

2. Tujuan Tindakan Kedokteran Yang Dilakukan;

3. Alternatif Tindakan Lain dan Resikonya

4. Resiko dan Komplikasi Yang Mungkin Terjadi

5. Prognosis Terhadap Tindakan Yang Dilakukan;

6. Perkiraan Biaya.

\section{Rumusan Masalah}

Berdasarkan uraian diatas, maka dapat dirumuskan dalam suatu Rumusan Masalah yaitu :

1. Bagaimanakah Bentuk Tanggung Jawab Tenaga Kesehatan Berdasarkan Informed Consent Dalam Perjanjian terapeutik Rumah Sakit di Provinsi Bali?

2. Bagaimanakah Upaya Penyelesaian Sengketa Medik Yang Dapat Dilakukan Pasien/Keluarga Pasien Terhadap Resiko Dalam Informed Consent Rumah Sakit di Provinsi Bali?

\section{Tujuan Penelitian}

Secara umum penelitian ini bertujuan untuk mengetahui implementasi persetujuan tindakan kedokteran (Informed Consent) dalam perjanjian terapeutik oleh tenaga kesehatan terhadap pasien rumah sakit di Provinsi Bali.

Adapun tujuan khusus penulisan ini adalah :

1. Untuk mengetahui bentuk tanggung jawab tenaga kesehatan berdasarkan informed consent dalam perjanjian terapeutik rumah sakit di provinsi Bali.

2. Untuk mengetahui upaya penyelesaian sengketa medik apa yang dapat dilakukan pasien/keluarga pasien terhadap resiko informed consent rumah sakit di provinsi Bali. 


\section{METODE PENELITIAN}

Metode penelitian yang digunakan dalam penelitian ini adalah penelitian hukum empiris dengan sumber data primer dan data sekunder. Penelitian bersifat deskriptif, dengan analisis data kualitatif. Seluruh hasil analisis tersebut disajikan secara deskripsi yaitu memaparkan permasalahan yang diteliti dengan disertai ulasanulasan yang kritis.

\section{HASIL DAN PEMBAHASAN}

\section{Implementasi}

Informed

Consent Dalam Perjanjian Terapeutik Rumah Sakit di Provinsi Bali Upaya Hukum Pasien Terhadap Resiko Dalam Informed Consent Rumah Sakit Di Provinsi Bali

\section{a. Implementasi Informed} Consent Dalam Perjanjian Terapeutik Rumah Sakit di Provinsi Bali

Hubungan antara dokter sebagai tenaga medis dengan pasien terbentuk dari suatu perjanjian terapeutik yang menimbulkan hak dan kewajiban, oleh karena itu informasi dan penjelasan awal dari dokter sangat diperlukan sehingga pasien paham terhadap penyakit yang dideritanya. Dengan demikian dokter akan mengupayakan kesembuhan pasiennya dengan melakukan suatu tindakan kedokteran sesuai dengan standar profesi yang diembannya.

$$
\text { Informasi terhadap diagnosa }
$$

penyakit pasien harus dilakukan oleh dokter itu sendiri dan tidak boleh di delegasikan kepada perawat. Hal ini juga akan membahayakan bagi dokter itu sendiri karena pada akhirnya tanggungjawab tetap ada pada dokter. selain itu bukan wewenang perawat dalam memberikan informasi terhadap pasien. $^{4}$

Dalam kenyataannya masih terdapat ketidaksesuaian terhadap permberian informasi dan tindakan kedokteran di rumah sakit. emberian

\footnotetext{
${ }^{4}$ Guwandi, 2005, Rekam Medis, Balai Penerbit Fakultas Kedokteran Universitas Indonesia, Jakarta, hal 31.
} 
informasi, tindakan kedoteran dan pengisian form persetujuan tindakan kedokteran (Informed Consent) masih sering didelegasikan kepada perawat/bidan padahal bukan merupakan kewenanganya.

Menurut Prof. Mr.S.B.Van Der Mijn, dalam melaksanakan tugas profesinya, seorang tenaga kesehatan harus berpegang pada tiga ukuran atau standar medik umum yaitu kewenangan, kemampuan rata-rata dan ketelitian yang umum. ${ }^{5}$

\section{Buku panduan Akreditasi}

Rumah Sakit Tahun 2012, menjelaskan bahwa salah satu cara melibatkan pasien dalam pengambilan keputusan tentang pelayanan yang diterimanya adalah dengan cara memberikan Informed Consent. Untuk menyetujui tindakan yang dilakukan tenaga kesehatan, pasien harus diberi penjelasan terlebih dahulu tentang hal-hal yang berhubungan dengan pelayanan yang direncanakan, karena diperlukan untuk suatu keputusan persetujuan.

5 Wila Chandrawila Supriadi, 2001, Hukum Kedokteran, Bandar Maju, Bandung, hal 23.
Dalam penelitian yang dilakukan terhadap 25 Responden dan 10 informan yang dilakukan dengan wawancara dan observasi langsung ke rumah sakit di provinsi Bali, pemberian informasi dalam bentuk Informed Consent mulai diupayakan lebih awal, namun upaya tersebut belum dilakukan secara maksimal.

Hal tersebut dipengaruhi oleh beberapa hal yang dapat penulis rangkum, yaitu :

1. Kondisi pasien yang memerlukan pertolongan dengan segera, sehingga baik pasien ataupun keluarga dengan cepat mengatakan telah mengerti dengan apa yang disampaikan oleh dokter;

2. Informasi yang disampaikan oleh tenaga kesehatan tidak dipahami oleh pasien;

3. Sistem pelayanan rumah sakit yang tidak fleksibel, artinya pasien merasa dipersulit dalam kondisi dirinya yang memerlukan pengobatan; 
4. Pemberian informasi sampai pada memintakan tandatangan di lembar consent terkadang dilakukan oleh perawat padahal itu adalah wewenang dokter;

5. Pasien sering tidak diberi kesempatan untuk membaca kembali formulir yang diberikan, sehingga pasien merasa tidak pernah diberikan informasi sebelum dilakukan tindakan kedokteran.

6. Sumber Daya Manusia yang belum memadai seperti kurangnya tenaga kesehatan di rumah sakit sehingga tidak mampu memenuhi kebutuhan pelayanan kesehatan

Untuk mengkaji permasalahan tersebut, digunakan Teori Sistem Hukum seperti yang dikemukakan oleh L. M. Friedman yang meliputi :

1. Struktur Hukum (legal structure);

Struktur hukum adalah Bagian-bagian yang bergerak di dalam suatu mekanisme sistem atau fasilitas yang ada dan disiapkan dalam sistem. yang dimaksud struktur hukum dalam penelitian ini adalah Rumah Sakit yang merupakan bagian dari struktur institusi.

2. Substansi Hukum (legal substance);

substansi adalah aturan, norma, dan pola perilaku nyata manusia yang berada dalam sistem itu. Dalam penelitian ini yang dimaksud dengan substansi adalah aturan atau norma yang mengatur tentang kesehatan khususnya tentang rumah sakit dan termasuk di dalamnya adalah aturan tentang tenaga kesehatan dan persetujuan tindakan kedokteran.

3. Budaya Hukum (legal culture).

Budaya hukum merupakan kultur yang dapat dianalogikan pada keyakinan, nilai dan apa yang diharapkan dari adanya hukum dan sistem hukum oleh masyarakat Lembagalembaga penegak hukum juga termasuk ke dalam pelaksana 
hukum. Dalam penelitian ini, dapat dilihat bagaimana budaya hukum diterapkan yaitu melihat bagaimana tenaga kesehatan menerapkan aturan yang ada ke dalam praktek kegiatan penyelenggaraan kesehatan, sehinggga masyakat dapat menilai secara nyata apakah penyelenggaraan pelayanan di rumah sakit telah berjalan sesuai dengan aturan yang berlaku dan efektif.

b. Tanggung Jawab Tenaga Kesehatan dan Rumah Sakit Terhadap Resiko Bersadarkan Informed Consent

Tanggung jawab medis muncul akibat adanya perjanjian antara dokter dengan pasien menimbulkan hubungan hukum. Hubungan yang terjadi merupakan hubungan yang unik karena tidak hanya terdapat hubungan hukum, juga terdapat hubungan non hukum, hubungan medik, hubungan ekonomi dan hubungan sosial. Hubungan ini tidak dapat dilihat dari satu segi saja, namun juga harus dilihat dari berbagai segi yang tidak dapat dipisahkan satu sama lain.

Dalam pengertian hukum, tanggung jawab berarti keterikatan. Setiap manusia mempunyai hak dan kewajiban yang disebut sebagai subyek hukum. Demikian pula tenaga kesehatan, baik dokter, perawat maupun bidan dalam tindakan profesinya berkaitan erat dengan tanggungjawab khususnya tanggungjawab profesi.

Ada dua macam pertanggungjawaban yaitu pertanggungjawaban berdasarkan kesalahan (based on fault liability) dan pertanggungjawaban mutlak (absolute liability) $^{6}$

Seiring dengan perkembangan kemajuan dibidang ilmu (hukum) konsep tanggung jawab dalam arti liability ini makin dirasa perlu untuk membuat kualifikasi yang jelas atas pembagian tersebut agar tidak terjadi perbedaan

6 Hans Kelsen Dalam Asshiddiqie, Jimly Ali Safa'at, M, 2006, Teori Hans Kelsen Tentang Hukum, Sekretariat Jenderal dan Kepaniteraan Mahkamah Konstitusi RI, Jakarta, hal 61. 
yang akan berdampak pada tataran pengaplikasiannya nanti

Ditinjau dari hubungan hukum, tanggungjawab dokter dapat dilihat dari dua aspek, yaitu:

1. Tanggungjawab professional (verantwoordelijkheid);

2. Tanggungjawab hukum (aansprakelijkheid).

Dalam tanggung jawab hukum, tindakan kedokteran oleh tenaga kesehatan terhadap pasien harus dipertanggungjawabkan dan dapat diklasifikasikan sesuai dengan bidang hukum yang dilanggar : ${ }^{7}$

1. Tanggung Jawab

\section{Administrasi}

2. Tanggung Jawab Perdata

3. Tanggung Jawab Pidana

Perjanjian terapeutik melahirkan perikatan yaitu Perikatan Usaha (Inspanningsverbintenis) artinya bahwa dokter akan berusaha semaksimal mungkin memenuhi suatu prestasi. Secara yuridis, dipenuhi atau tidak dipenuhinya prestasi, tidak ditentukan oleh hasil melainkan oleh cara kerjanya.

7 Hasyim, Musruroh dan Prasetyo, Joko, 2012, Etika Keperawatan, Penerbitan Bangkit, Yogyakarta, hal 80.
Berdasarkan hasil penelitian ke terhadap 25 responden dan 10 informan ke rumah sakit di Provinsi Bali Teori serta berdasarkan Teori Tanggung Jawab dari Hans Kelsen, bahwa Bentuk Tanggung Jawab Tenaga Kesehatan Berdasarkan Informed Consent Dalam Perjanjian terapeutik Rumah Sakit di Provinsi Bali terletak pada dokter operator yang menandatangani form Informed Consent tersebut. Namun apabila pasien/keluarga pasien menuntut secara hukum tindakan kelalaian yang dilakukan oleh tenaga kesehatan, maka pihak rumah sakit akan ikut bertanggung jawab secara tanggung renteng terhadap kelalaian tersebut.

\section{Tanggung Jawab Tenaga Kesehatan dan Rumah Sakit Terhadap Resiko Bersadarkan Informed Consent}

\section{a. Peran Informed Consent} Dalam Upaya Penyelesaian Sengketa Medik

pemberian informasi oleh harus memiliki kesamaan bahasa atau setidaknya ada pendekatan dalam pengertian dari orang yang 
menerima informasi. Bila terdapat kesenjangan antara bahasa pemberi informasi, maka usaha pemberian informasi tidak akan mencapai tujuan.

\section{Bila informasi tidak mencapai} sasaran yang tepat, akan menimbulkan sengketa dikemudian hari. Demikian pula di rumah sakit, bila informasi tidak disampaikan secara tepat dan benar akan menimbulkan sengketa medis. oleh karena itu dengan memberikan informed consent sebagai sarana pemberian informasi maka dapat dijadikan sebagai alat bukti jika terjadi sengketa medik.

Informed consent sangat berperan dalam penyelesaian sengketa medik di rumah sakit. Salah satu dokumen yang dibuka pertama kali ketika terjadi sengketa medik adalah lembar Informed Consent atau lembar persetujuan tindakan kedokteran. Dari lembar Informed Consent, akan dilihat apakah sebelum tindakan sudah diberikan penjelasan sekurang-kurangnya mencakup diagnosis dan tata cara tindakan medis, tujuan tindakan medis yang dilakukan, alternatif tindakan lain dari risikonya, risiko dan komplikasi yang mungkin terjadi, dan prognosis terhadap tindakan yang dilakukan. Dari lembar Informed Consent juga akan terlihat, apakah pasien sudah memberikan persetujuan untuk dilakukan tindakan baik secara tertulis maupun lisan.

Leenan memberikan pendapat tentang isi dari informasi yang diberikan oleh tenaga kesehatan kepada pasien antara lain :

1. Diagnose;

2. Terapi, dengan kemungkinan alternatif terapi;

3. Tentang cara kerja dan pengalaman dokter;

4. Resiko;

5. Kemungkinan perasaan sakit ataupun perasaan lainnya (misalnya gatal-gatal);

6. Keutungan terapi

7. Prognose.

Ketidakpahaman pasien terhadap Informed Consent sering menjadi persoalan dan Sengketa Medik di Rumah Sakit. Sengketa medik di rumah sakit dapat berwujud pengaduan, dapat disertai atau tanpa 
malapraktik. Namun bila dalam tindakan kedokteran menggunakan Informed Consent sebagai dasar, maka akan dapat meminimalisir tingkat kesalahan/kelalaian yang dilakukan tenaga kesehatan dan memberikan perlindungan hukum kepada semua pihak.

Sebagaimana fungsi informed consent yaitu sebagai alat bukti dalam proses penegakan hukum, disiplin kedokteran, penegakan etika kedokteran dan kedokteran gigi membantu penyelesaian sengketa medik dengan ikut menentukan, apakah berdasarkan catatan tenaga kesehatan tersebut, terdapat kelalaian, kesengajaan, ketidakmampuan atau kesalahan dalam prosedur tindakan yang dilakukan, maka perikatan yang terjadi antara rumah sakit dengan pasien adalah perikatan yang sifatnya ikhtiar, sehingga jika ada kerugian yang diakibatkan oleh pelayanan atau tindakan tenaga kesehatan di rumah sakit maka rekam medis yang di dalamnya terdapat Informed Consent akan menjadi rujukan pertama, karena disana tercatat semua pelayanan dan tindakan yang diterima oleh pasien.

Dari lembar Informed Consent, akan dilihat apakah sebelum tindakan sudah diberikan penjelasan sekurang-kurangnya mencakup diagnosis dan tata cara tindakan medis, tujuan tindakan medis yang dilakukan, alternatif tindakan lain dari risikonya, risiko dan komplikasi yang mungkin terjadi, dan prognosis terhadap tindakan yang dilakukan, serta akan terlihat apakah pasien sudah memberikan persetujuan untuk dilakukan tindakan baik secara tertulis maupun lisan.

\section{b. Upaya Penyelesaian Sengketa Medik Terhadap Resiko Di Rumah Sakit Provinsi Bali}

Dokter adalah profesi yang banyak berhubungan langsung dengan banyak orang yang memerlukan pertolongan, tetapi profesi tersebut tidak terlepas pula dengan resiko yang berujung pada tuntutan financial dari pasien.

Resiko adalah suatu kondisi yang memandang kemungkinan 
terjadinya penyimpangan yang lebih buruk dari hasil yang diharapkan. Resiko memiliki sejumlah pengertian antara lain : ${ }^{8}$

1. The Chance Of Loss (Kesempatan timbulnya kerugian);

2. The Possibility of Loss (Kemungkinan timbulnya kerugian);

3. Uncertainty (Ketidakpastian);

4. The Dispersion Of Actual From Expected Result ( Penyebaran dari hasil yang diperkirakan);

5. The Probability of Any Outcome Different From The Excpected One (Kemungkinan suatu hasil akhir berbeda dengan yang diharapkan)

Umumnya yang sengketakan dalam sengketa medik adalah hasil atau hasil akhir pelayanan kesehatan dengan tidak memperhatikan atau mengabaikan prosesnya. Padahal dalam hukum kesehatan diakui bahwa tenaga kesehatan atau

8 Emmet J. Vaughan \& Therese Vaughan, 2002, Fundamental of Risk and Insurance, $9^{\text {th }}$ Edition, John Wiley \& Sons, Inc, United States of America, Page 3. pelaksana pelayanan kesehatan saat memberikan pelayanan hanya bertanggung jawab atas proses atau upaya yang dilakukan (Inspanning Verbintennis) dan tidak menjamin hasil akhir (Resultalte Verbintennis).

Sengketa medis dapat pula muncul ketika dalam periode pra perawatan, saat perawatan maupun pasca perawatan. Selain itu dapat pula muncul dalam ranah kode etik maupun ranah yuridis. Sengketa medis pra perawatan dapat terjadi pada saat penerimaan awal (pendaftaran, kegawatdaruratan) biasanya disebabkan oleh pelayanan tenaga kesehatan yang kurang ramah, kurang cepat, waktu menunggu yang lama, sehingga pasien/ keluarga pasien merasa ditelantarkan. Sedangkan pada masa perawatan biasanya disebabkan karena komunikasi yang kurang efektif karena banyaknya pasien yang datang ke rumah sakit. pada masa pasca perawatan biasanya disebabkan karena pembiayaan yang harus ditanggung cukup besar, hasil dari perawatan tidak sesuai dengan harapan sehingga muncul efek samping atau resiko medis lainnya. 
Alur Penyelesaian Sengketa

Medik di Rumah Sakit adalah dengan cara membedakan antara masalah etik dan hukum (hukum pidana, hukum perdata dan hukum administratif), mengecek semua peraturan yang terkait, (termasuk Kode Etik Kedokteran dan Kode Etik Rumah Sakit), menganalisa kasus dalam case review, serta menentukan posisi dokter dan pasien.

Soeraryo Darsono menyebutkan bahwa alur penyelesaian sengketa medik di rumah sakit adalah: ${ }^{9}$

1. Bedakan antara masalah etik dan hukum (hukum pidana, hukum perdata dan hukum administratif);

2. Cek semua peraturan yang terkait, termasuk Kode Etik Kedokteran, Kode Etik Rumah Sakit;

3. Analisa kasus dalam case review;

4. Tentukan "posisi" dokter pasien.

${ }^{9}$ Soeraryo Darsono, 2003, Perlindungan Hukum Bagi Dokter, Makalah disampaikan dalam rangka HUT RSUP Dr. Soeradji Tirtonegoro, Klaten.
Terdapat dua cara penyelesaian sengketa medik yaitu melalui Jalur hukum yang terdiri dari Hukum Pidana dan Perdata dan melalui Jalur Etika Profesi Kedokteran Indonesia yaitu dengan MKEK dan P3EK. ${ }^{10}$

Dalam menyelesaikan kasus Perdata, biasanya terdapat dua jalur yang menjadi penawaran bagi pihak yang bersengketa jalur litigasi dan non-litigasi. Yang dimaksud dengan Litigasi adalah bentuk penanganan kasus melalui jalur proses di peradilan baik kasus perdata maupun pidana, sedangkan Non-Litigasi adalah penyelesaian masalah hukum diluar proses peradilan. Non litigasi ini pada umunya dilakukan pada kasus perdata saja karena lebih bersifat privat. Non litigasi mempunyai beberapa bentuk untuk menyelesaikan sengketa yaitu:

1. Negosiasi

2. Mediasi

3. Arbitrase

${ }^{10}$ Halim, A. Ridwan, 2006, Penyelesaian Sengketa Medik Antara Dokter dan Pasien Melalui Jalur Hukum dan Jalur Etika Profesi Kedokteran Indonesia; Fakultas Hukum Unika Atma Jaya; Jakarta, hal 18. 
Ketiga bentuk penyelesaian sengketa dilakukan oleh pihak yang merasa dirugikan atau terjadinya perbedaan pendapat baik itu antara individu, kelompok maupun antar badan usaha. Penyelesaian sengketa melalui jalur non litigasi dilakukan untuk menyelesaikan sengketa dengan cara musyawarah mufakat dan hasil penyelesaian konflik atau sengketa secara kekeluargaan.

Berdasarkan penelitain yang penulis lakukan, bahwa upaya penyelesaian sengekta medik rumah sakit di provinsi bali, dilakukan dengan jalan kekeluargaan. Mediasi merupakan salah satu jalan yang ditempuh bila terjadi sengketa medik di rumah sakit di provinsi Bali. Melalui mediasi akan tercipta winwin solution, tidak ada yang kalah dan tidak ada yang menang sehingga hubungan dokter dan pasien tetap harmonis.

\section{SIMPULAN DAN SARAN}

\section{Simpulan}

a. Bentuk Tanggung Jawab Tenaga Kesehatan Berdasarkan Informed
Consent Dalam Perjanjian terapeutik Rumah Sakit di Provinsi Bali terletak pada dokter operator yang menandatangani form Informed Consent tersebut. Namun apabila pasien/keluarga pasien menuntut secara hukum tindakan kelalaian yang dilakukan oleh tenaga kesehatan, maka pihak rumah sakit akan ikut bertanggung jawab secara tanggung renteng terhadap kelalaian tersebut.

b. Upaya penyelesaian sengekta medik rumah sakit di Provinsi Bali, dilakukan dengan jalan kekeluargaan, salah satunya dengan jalan mediasi dengan dasar pertimbangan adalah Pasal 29 Undang-Undang Nomor 36 Tahun 2009 tentang Kesehatan.

\section{Saran}

$$
\text { Adapun saran yang dapat }
$$
penulis sampaikan pada penelitian ini antara lain : 
1. Diharapkan agar pasien lebih waspada dan aktif bertanya kepada tenaga kesehatan khususnya tenaga medis (dokter), agar terjalin komunikasi yang baik dalam melakukan tindakan kedokteran terutama yang mengandung resiko yang tinggi.

2. Diharapkan agar pasien memahami akan hak dan kewajibannya sebagai pasien sehingga tidak saling menyalahkan ketika terjadi resiko terhadap tindakan kedokteran oleh tenaga kesehatan.

3. Diharapkan dokter lebih berhati-hati dalam melakukan tindakan kedokteran terhadap pasien di rumah sakit khususnya dalam tindakan kedokteran yang mengandung resiko tinggi.

4. Diharapkan dokter selalu memberikan informasi yang selengkap-lengkapnya kepada pasien baik diminta ataupun tidak sebelum melakukan tindakan kedokteran. Informasi yang disampaikan dokter sebaiknya dicatat dalam form Informed Concent serta ditanyakan kepahaman pasien akan penjelasan dokter dan menyatakan persetujuannya dengan menandatangani Informed Concent tersebut.

5. Diharapkan kepada rumah sakit khususnya di provinsi Bali agar memberikan pelayanan sesuai standar prosedur dengan berpedoman pada akreditasi rumah sakit sehingga dapat mewujudkan hubungan yang harmonis antara pasien, tenaga kesehatan dan rumah sakit itu sendiri.

\section{Daftar Pustaka}

Jusuf Hanafiah dan Amri Amir, Etika Kedokteran dan Hukum Kesehatan, Jakarta, EGC, 2008.

Harmien Hadiati Koeswadji, Hukum Kedokteran di Dunia 
Internasional, Makalah Simposium, Medical Law, Jakarta, 1993.

Salim HS, Perkembangan Hukum Kontrak di Luar KUH Perdata, Rajawali Press, Jakarta, 2006.

Wila Chandrawila Supriadi, Hukum Kedokteran, Bandar Maju, Bandung, 2001.

Hasyim, Musruroh dan Prasetyo, Joko, Etika Keperawatan, Penerbitan Bangkit, Yogyakarta, 2012.

Soeraryo Darsono, 2003, Perlindungan Hukum Bagi Dokter, Makalah disampaikan dalam rangka HUT RSUP Dr. Soeradji Tirtonegoro, Klaten
Halim, A. Ridwan, Penyelesaian Sengketa Medik Antara Dokter dan Pasien Melalui Jalur Hukum dan Jalur Etika Profesi Kedokteran Indonesia; Fakultas Hukum Unika Atma Jaya; Jakarta, 2006.

Emmet J. Vaughan \& Therese Vaughan, 2002, Fundamental of Risk and Insurance, $9^{\text {th }}$ Edition, John Wiley \& Sons, Inc, United States of America

Hans Kelsen Dalam Asshiddiqie, Jimly Ali Safa'at, M, Teori Hans Kelsen Tentang Hukum, Sekretariat Jenderal dan Kepaniteraan Mahkamah Konstitusi RI, Jakarta, 2006 